\title{
Comentários sobre a vocalitá no período de transição da ópera Italiana
}

\section{Marcos da Cunha Lopes Virmond Lenita Waldige Mendes Nogueira}

Resumo: O Período de Transição na ópera italiana do século XIX compreende os anos de 1870 até 1890 . As características definidoras deste período são uma rejeição definitiva da forma solita Rossiniana, a construção flexível do drama musical, a rejeição gradual da ópera de números e a adesão ao modelo francês da grande ópera. G. Verdi torna-se recluso, compondo apenas Aida e Otello e uma janela de oportunidade se abre por um breve período e, pelo menos, dois nomes - Amilcare Ponchielli e Antônio Carlos Gomes - aproveitam esta oportunidade para apresentar sua produção. $O$ objetivo deste artigo é descrever brevemente esse período da ópera italiana e discutir uma de suas características, a vocalitá usada pelos compositores deste período relevante para a história da ópera italiana. O drama se torna o ponto principal do canto e as acrobacias vocais tornaram-se sem sentido em oposição aos princípios do bel canto. O compositor mudou sua maneira de escrever, de uma vocalitá ornamental, melismática para uma silábica. Cada palavra, cada sílaba é importante e a compreensão do que os cantores cantaram é agora mais relevante. Assim, o termo vocalitá pode ser entendido como a característica vocal de uma música ou a forma como um compositor usa a voz em sua composição: isto é, a qualidade da música vocal sob um determinado compositor ou período estilístico.

Palavras-chave: Ópera italiana. Vocalitá. Composição. Amilcare Ponchielli. Carlos Gomes

Abstract: The Transition Period in the $19^{\text {th }}$ Italian opera ranges from $1870-$ 1890. Defining characteristics of this period are a definitely rejection of the Rossinian solita forma, flexible construction of the musical drama, gradual rejection of the number opera and adhesion to the French grand-opera model. A reclusion of G. Verdi is also noted, apart from Aida and Othello and a window of opportunity opens for a brief period and, at least, two important names - Amilcare Ponchielli and Antonio Carlos Gomes - take this opportunity to present their production. The aim of this article is precisely to briefly describe this period of the Italian opera and to discuss one of its 
characteristic, the vocalitá as used by composers of this short although relevant period to the history of the Italian opera. The drama becomes the main point of singing and vocal acrobatics became senseless as opposed to the principles of the bel canto. Composer changed their way of voice writing from ornamental, melismatic to a syllabic vocalitá. Each word, each syllable is important and the understanding of what singers sang is now more and more relevant. Thus, the term vocalitá may be understood as the vocal characteristic of a music or the way a composer uses the voice in its composition: i.e, the quality of vocal music under a given composer or stylistic period.

Keywords: Italian opera. Vocalitá. Composition. Ponchielli. Gomes.

\section{Introdução}

De maneira linear, a ópera italiana começa com Monteverdi, estabelece sua forma com Rossini, atinge sua grandeza e fama com Verdi e morre com Puccini. Claro, esta é uma linha de tempo muito simples para um gênero tão importante e complexo que floresceu de forma única na Itália. Na verdade, com algumas exceções, como Wagner na Alemanha, a ópera no mundo é uma derivação próxima da estrutura do que a Itália propôs para o gênero. No entanto, nenhum gênero desafiou tantos compositores em todo o mundo como a ópera. Da Argentina ao Canadá, do México a Tóquio, a ópera tem sido um gênero atraente cujo desafio os compositores raramente recusam enfrentar. Números conservadores indicam que mais de 20.300 óperas foram compostas no mundo ocidental até 1905 (Clemente e Larousse, 1905).

Mais interessante, na Itália, a variedade e número de óperas composta no século 19 é impressionante, contando-se milhares de títulos. Muito provavelmente, alguns deles alcançaram os palcos e, dentre esses, apenas uma dúzia, talvez, permaneceu no repertório estável da península por mais de 1 ano. De fato, nomes como Rossini, Donizetti, Bellini, Mercadante, Pacini, Petrella e Verdi foram os poucos importantes compositores nativos da primeira metade do século XIX na 
Itália. Ao redor deles, uma multidão de nomes menores circulava com algum sucesso. Razões para isso incluem as necessidades dos teatros de província exigindo novos títulos para atender às expectativas de um número crescente de compradores de ingressos. Mantendo as devidas dimensões, a relação era semelhante à da indústria cinematográfica americana na primeira metade do século 20 , que produziu uma grande quantidade de filmes de classe A e B - cada um deles tinha seu púbico e sua razão de ser. $O$ importante era manter o mercado bem suprido. Nesse sentido, há uma lista quase infinita de compositores de óperas italianas que forneceram títulos para cumprir com essa necessidade. Muitos deles ainda são conhecidos como importantes compositores. Este é o caso de Amilcare Ponchielli, Carlos Gomes, Felippo Marchetti, Alfredo Catalani, Arrigo Boito, Franco Faccio e outros. A lista de compositores menores é longa e inclui Francesco e Luigi Ricci, Franco Vittadini, Stefano Gobatti, Cagnoni, Baraldi, Bottesini, Usiglio e muitos outros.

Apesar desse mundo efervescente do negócio da ópera, não há dúvidas de que a música de alta qualidade ficou restrita a alguns compositores, a saber, Rossini, Bellini, Donizetti, Mercadante, Verdi e Pucinni se considerarmos um período de tempo entre 1810 e aproximadamente 1900. Neste período, pelo menos três escolas estilísticas dominaram: a segunda escola de Bel Canto (Rossini, Bellini, Donizeti), o período Verdiano maduro e a Giovane Scuola (Puccini, Mascagni, Franchetti, Leoncavallo, etc.). Outra possibilidade é considerar estas três escolas ao longo de dois largos períodos, a ópera italiana romântica e pós-romântica, que começa em 1870. Notável é o fato de que Verdi, devido à sua longevidade e longa produtividade, participou em todos esses períodos com presença marcante.

Uma vez estabelecidas essas premissas, chama-se a atenção agora para um período estilístico peculiar que ocorreu na década de 1870 e que permaneceu quase despercebido pela musicologia internacional - o Período de Transição. O objetivo deste artigo é precisamente descrever brevemente este período da ópera italiana, 
caracterizar e discutir uma de suas características, a vocalitá usado pelos compositores deste período curto embora relevante para a história da ópera italiana do século XIX.

\section{O Período de Transição}

Considerando o silêncio de Gioacchino Rossini após a estreia de Guglielmo Tell em 1829, a perda precoce de Vincenzo Bellini em 1835 e a morte de Gaetano Donizetti em 1848, o melodrama lírico permaneceu nas mãos de Giuseppe Verdi por um longo tempo. Certamente, neste período até o início dos anos 1870, vários outros compositores gravitaram, com maior ou menor presença, em torno dos teatros peninsulares, mas sem alcançar a eficiência estética do mestre de Busetto. Os motivos dessa atividade contínua são as necessidades econômicas, a pura necessidade de diversão e, de maior relevância, o melodrama lírico foi um elemento de coalisão em torno do processo de unificação da Itália e criação de uma identidade para o povo da península.

No entanto, no final dos anos 1860 está claro que a influência francesa está se tornando mais evidente no sempre protegido melodrama italiano. Meyerbeer e a Grande Opéra francesa se tornam uma obrigação entre os frequentadores da ópera italiana. A jovem intelectualidade do norte da Itália está em turbulência. Eles expressam seu desconforto através do movimento dos scapigliati. Embora limitado principalmente a Milão e Turim, o grupo pretendia criar uma nova e moderna estética italiana em várias áreas artísticas com o objetivo de se aproximar de um estilo internacional. Eles procuram uma revolução para uma renovação que era cada vez mais difícil de evitar. Verdi claramente entendeu seus objetivos e não participou dessa "abertura" das tradições italianas. Por este e outros motivos, por um breve período, parece que o grande compositor permanece em hibernação. Nada realmente novo lhe 
sai da pena. Além disso, Verdi parece se divorciar de Milão. La Forza del Destin é estreada em São Petersburgo (1862) e Don Carlos é composta para Paris (1867). Itália e Milão não parecem estar na mente do compositor. Além dessas duas principais óperas, Verdi permanece por muito tempo revisando velhas óperas. Algo novo aparece apenas em 1871 com Aida. Os editores, em particular a casa Ricordi, veem com grande preocupação o silêncio do compositor e lançam seus olhos e ouvidos em busca de outras possibilidades que possam satisfazer a necessidade de "novas" óperas para os teatros onde, agora, atuam como empresário. Este período é principalmente oportuno para compositores de outros níveis que não o do grande Verdi. Esta é a oportunidade para eles mostrarem suas obras. Uma janela de oportunidade se abre por um breve período e, pelo menos, dois nomes importantes - Amilcare Ponchielli e Antônio Carlos Gomes - aproveitem esta oportunidade. Este é o período conhecido como o Período de Transição.

Este período é detalhadamente discutido por Nicolaisen (1980), embora ele prefira um termo amplo como "ópera italiana em transição". Nesse sentido, Cesare (2000) é efetivo na introdução com muita clareza do termo "período de transição". Quanto à fixação do período, os autores divergem. Nicolaisen $(1980$, p. 6) estabelece Verdi como os limites deste período, usando Aida e Falstaff como seus pontos de referência. Portanto, para Nicolaisen o período se estende de 1871 a 1893. Pode-se entender que Verdi seja o ponto de referência imediata sempre que se escreve sobre a ópera italiana do século XIX, e esse é o caso de Nicolaisen e Gosset (2006). No entanto, ao discutir o Período de Transição, Verdi é definitivamente um espectador secundário. Neste contexto, Cesare é correto em propor 1870-1890 como as datas limites para o período de transição. Razões para esses limites são a afirmação do modelo francês da grand-opéra no cenário italiano e o início do Giovane Scuola com Cavalleria Rusticana em 1890. Verdi faz parte disso? Até certo ponto, não. No entanto, ele era sábio e crítico o suficiente para escrever Aida exatamente no estilo da grand-opéra e, muitos anos mais 
tarde, Otello e Falstaff em uma estética completamente distinta do seu habitual, com um claro privilégio do discurso orquestral para nos brindar com duas das mais belas obras do repertório operístico mundial.

Seria fora do foco deste artigo apresentar e discutir extensivamente as características da ópera do Período de Transição. No entanto, alguns deles devem ser mencionados: uma rejeição definitiva da solita forma de Rossini (Powers, 1987), construção flexível do drama musical, rejeição gradual da ópera de número e adesão ao modelo da grand-opéra francesa. Como mencionado anteriormente, dois compositores são particularmente ativos neste período - Amilcare Ponchielli e Antônio Carlos Gomes - e merecem maior investigação do seu estilo composicional, estilo este que os torna característicos para esse período. Alguns desses aspectos já foram discutidos (Virmond, 2012), portanto, propomos neste artigo investigar e discutir a maneira como estes dois compositores utilizaram de forma singular a voz humana para criar seu próprio discurso dramatúrgico, ou seja, a vocalitá.

\section{O fim da era do bel canto}

O termo vocalitá pode ser entendido como a característica vocal da peça de música ou a forma como um compositor usa a voz em sua composição: a qualidade da música vocal sob um determinado compositor ou período estilístico. No seu sentido mais amplo, vocalitá também pode significar as características vocais de uma determinada voz, bem como detalhes particulares da voz de um determinado cantor. Para o propósito deste artigo, restringiremos nossa discussão sobre o primeiro significado que difere consideravelmente do segundo conceito.

Amilcare Ponchielli nasceu em 1834 e Antônio Carlos Gomes em 1836 e ambos, em épocas diferentes, estudaram no Conservatório de Milão tendo Francesco Rossi e Alberto Mazzucato como professores. Apesar das novas ideias e da modernidade de Mazzucato, é claro que 
ambos os compositores tiveram uma forte influência estética da estrutura padrão da ópera da primeira metade do século XIX. Por razões diferentes e geográficas, Ponchielli e Gomes tiveram uma carreira com duas fases muito distintas. Ponchielli tornou-se um mestre de banda e compositor de ópera quase desconhecido (I Promessi Sposi, La Savoiarda) na década de 1860 até se tornar famoso com o sucesso de uma segunda versão de sua primeira ópera / Promessi Sposi após uma revisão de Emilio Praga, o poeta scpapigliati, e uma bem-sucedida apresentação em 1872 no Teatro Dal Verme em Milão, o que chamou a atenção de Ricordi, o editor. Por sua vez, Gomes teve seu sucesso inicial limitado ao Rio de Janeiro com A Note do Castello (1871) e Joana de Flandres (1863) (Nogueira, 2013). Seu segundo período começa em 1864 no Conservatório de Milão e sua carreira floresce com o impressionante sucesso de // Guarany que estreou no La Scala em março de 1970. Os paralelos não terminam aqui. Embora não íntimos, Gomes e Ponchielli eram bons amigos e compartilhavam o mesmo bairro de Maggianico, um distrito de Lecco, uma pequena cidade de veraneio à beira do Lago de Como, perto de Milão.

Metastasio, nos anos 1770, costumava dizer que os cantores de sua época não cantavam, mas na verdade tentavam fazer som com a garganta (suonare colla gola) (Celletti, 1974, p. 81) A crise do antigo bel canto barroco baseado nos castrati parece resolver-se em Rossini com sua nova abordagem aos princípios do bel canto, mas agora sob sua concepção pessoal e levando em consideração o fim do esplêndido período dos castrati. Deve-se recordar que o bel canto é principalmente um estilo de canto particular aos castrati, caracterizado pela grande flexibilidade da voz desses cantores. Outras características deste estilo incluem uma ornamentação florida e delicada nas óperas belcantísticas e a necessidade de uma voz leve e flexível (Rutherford, 2006, p. 90). Rossini vai mais longe e estabelece a segunda escola belcantística que sobrevive até 1829, quando ainda usa alguns dos antiquados recursos, como o recitativo secco, mas definitivamente introduz um novo modelo 
de dueto que evoluirá progressivamente e amadurecerá como uma contribuição única de Rossini para seus seguidores, entre eles, Donizetti e Bellini. Entretanto, deve se salientar que estes dois compositores ainda usaram a estética do bel canto neste novo modelo. Uma inovação exclusiva de Bellini é o uso concentrado de um ritmo repetido e o emprego de uma linha melódica solitária e contínua, cujo clímax deixado para o final do período. Além disso, Bellini abandona as fiorituri tradicional de Rossini e limita o embelezamento da linha melódica aos grupetos e às apogiaturas. Progressivamente, os ornamentos são escritos pelos compositores e deixa-se muito pouca liberdade aos cantores para improvisar ou usar a vocalidade para demonstrar puramente suas habilidades vocais.

O fim do longo reinado do bel canto vem com a era romântica na música que, de forma constante e implacável, entra no mundo da ópera italiana pelas mãos de Verdi. No sentido amplo, o drama é o centro do canto e as acrobacias vocais tornaram-se inúteis e sem sentido em oposição aos princípios do bel canto. Os compositores mudam seu modo de escrita da voz, de ornamental, merismático para silábico. Cada palavra, cada sílaba é importante e a compreensão do que os cantores cantam agora é cada vez mais relevante. A palavra tem relevância. Os libretos mudam. O homem e o infortúnio humano são o centro do drama. Sem deuses e heróis - mesmo nos temas históricos importantes, as emoções naturais da alma humana estão constantemente no palco sendo um rei ou um trabalho, um guerreiro ou um sacerdote.

\section{Vocalitá}

O tratamento vocal para uma nova abordagem difere sensivelmente do bel canto. Com Verdi surge uma acentuada transformação. Há uma modificação do modelo alegórico e idealista do bel canto de Rossini para uma abordagem da verdade dramática através 
de uma voz "parlata" e "declamata" (Cellenti, 1974, p.82). A linha vocal tende, portanto, a se tornar mais direta e intimamente ligada às necessidades dramáticas do texto. Na verdade, o romantismo estava em busca de um acento mais realista, que é uma característica da linha vocal silábica. Em termos técnicos, evitar vocalizes em favor do canto silábico significa evitar uma emissão mais leve, ágil e fluida por tipo de canto que poderá a soar um pouco mais áspero e tenso. Além disso, os compositores procuravam um discurso mais dramático através de uma elevação na tessitura e para conseguir algum efeito na linha vocal silábica, prefeririam uma zona vocal mais apaixonada e excitante, ou seja, a parte mais aguda da tessitura vocal (Cellenti, 1984, p. 82). Na verdade, Verdi costumava compor música para as palavras à fim de produzir drama e estabelecer comunicação entre o palco e o público (Senici, 2004, página 88). É bem conhecida a tendência de Verdi para definir o foco da vocalitá de seus cantores no registro agudo. Um exemplo é o barítono Verdiano que, na maioria das vezes, canta quase perto da tessitura do tenor. Diferentemente do barítono lírico, a voz de barítono padrão para as óperas de Bellini e Donizetti, o barítono Verdiano possui um volume de voz capaz de competir com a orquestra completa, uma tessitura grave capaz de "projeção" e, mais notavelmente, uma tessitura aguda com brilho e força (Miller, 2008, página 9). Neste contexto, é interessante notar que alguns dos barítonos de Gomes apresentam um comportamento diferente. Ao estudar a frequência das notas utilizadas por Gomes para Masaniello (Salvator Rosa) (1874) e Don Gil (Maria Tudor) (1879), a linha vocal é principalmente centrada em A3 e B3. No entanto, em termos de tessitura, é possível notar que o primeiro é um típico barítono Verdiano, cantando na proximidade da tessitura do tenor e o segundo mostra que as notas da tessitura proposta são mais uniformemente distribuídas, denotando um vocalitá com tendência ao registro do barítono lírico (Figura 1$)^{1}$.

1 O estudo da frequência foi limitado à análise da frequência de novas notas diferentes, independentemente da sua duração, aparecendo na linha vocal de 
Figura 1 - Gráfico apresentando a frequência de novas notas na linha vocal de Masaniello e Don Gil ao longo da tessitura entre C3 e F4, sendo C4 o C central conforme a regra para notação.

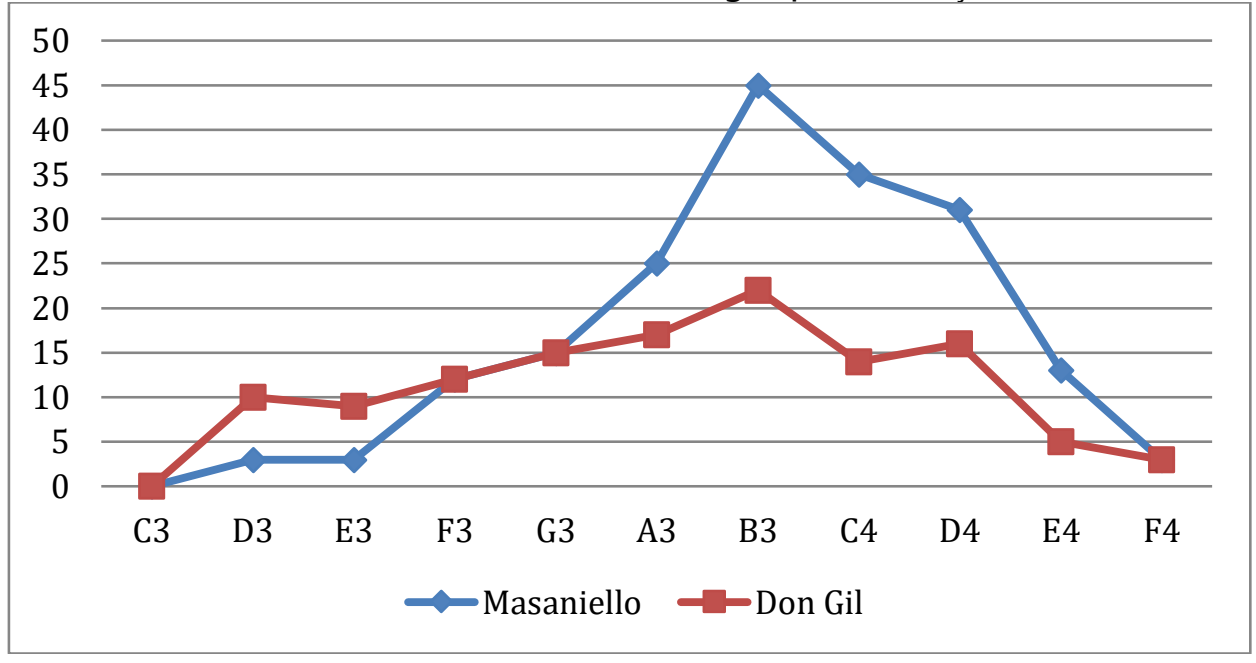

No caso de // Guarany e Lo Schiavo (Figura 2), o centro da voz é mais uniformemente distribuído, típico de um barítono lírico do bel canto, embora se possa notar uma tendência para que lberè use toda a tessitura de sua voz e, além disso, que ambos os papéis vão ao G4, o que não acontece no exemplo de Masaniello e Don Gil.

No entanto, esta não é a única característica da vocalitá no sentido que nos propomos aqui para explicar. O uso de intervalos específicos ou arcos melódicos são outro conjunto de itens que fazem vocalitá uma característica de um determinado compositor ou um período estilístico.

Não é nossa intenção investigar todo o processo de composição do período romântico (Rossini, Bellini, Donizetti), bem como discutir as modificações marcadas que Verdi introduziu de forma constante para reorganizar o cânone de Rossin da ópera italiana romântica. O objetivo deste breve estudo é chamar a atenção para algumas características da linha vocal utilizada pelos compositores do Período de Transição e Salvator Rosa. A mesmo foi a metodologia para Don Gil em sua aria do quarto ato de Maria Tudor. 
propor que essas características, embora pequenas, sejam paradigmáticas de seu próprio estilo e distintas das grandes modificações introduzidas por Verdi.

Figura 2 - Gráfico que descreve a frequência de novas notas na linha vocal. $O$ estudo baseou-se na $2^{a}$ Canção do Aventureiro (// Guarany) para Gonzales e na aria de Iberè, $4^{\circ}$ Ato de Lo Schiavo. C4 é o C central de acordo com a notação americana

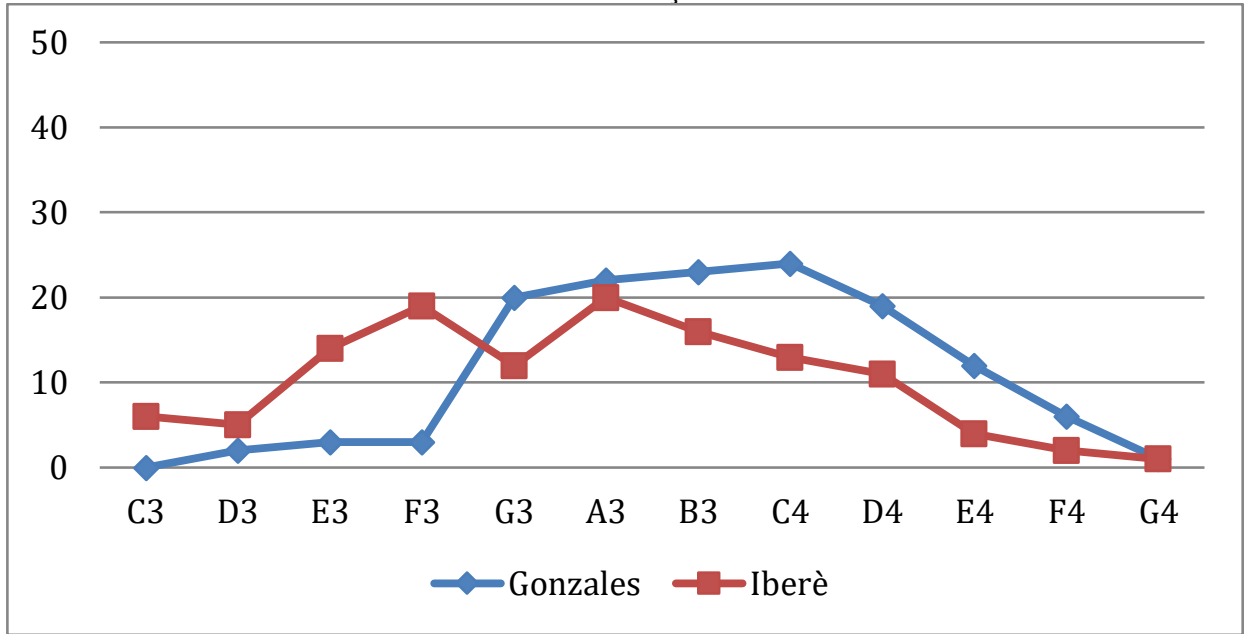

\section{Avocalitá de Ponchielli e Gomes}

Um exemplo possível deste novo estilo de trabalhar na linha vocal poderia ser, no período Verdiano tardio e no período de transição, o abandono da técnica usual de iniciar a linha melódica com o III grau da escala maior por meio de um salto ascendente da $6^{\text {a }}$ (Figura 3 ) e, mais frequentemente, através de um intervalo adicional de $4^{\circ}$. De fato, esta é uma característica ampla da ópera italiana romântica da primeira metade do século XIX. Portanto, quando o Verdi da maturidade e os compositores do período de transição evitam este procedimento muito Belliniano, pode-se considerar isso como uma característica própria desses compositores e desse período. 
Figure 3 - Bellini, / Capuleti e / Montecchi. Cavatina "Se Romeo t"ucise". 1 st Act.

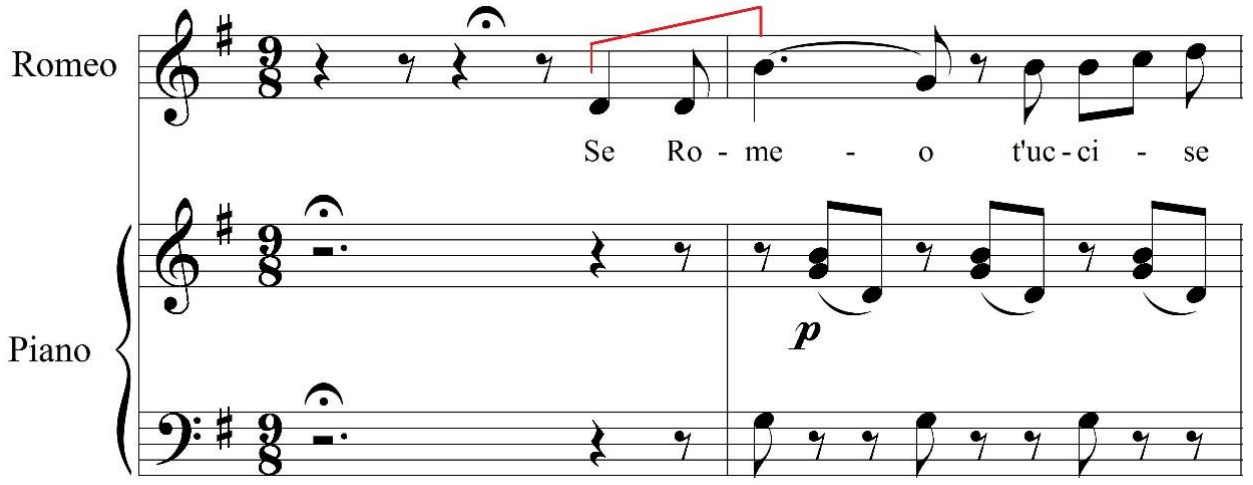

Embora não inédito, o canto silábico é a base do vocalitá do período de transição. As linhas com vocalização são raras. Nesse sentido, é interessante notar como Gomes administra a vocalitá de Cecilia em // Guarany. Para a introdução e caracterização da personagem leve e alegre, Gomes, no primeiro ato, apresenta Cecilia por uma Polacca cheia de roulades e cadenzas antiquados, uma forma tradicional de escrever a linha melódica para um soprano lírico romântico com habilidades de coloratura (Figura 4)

Figura 4 - A. C. Gomes. // Guarany. Sortita Cecilia. $1^{\circ}$ ato.

Cecilia

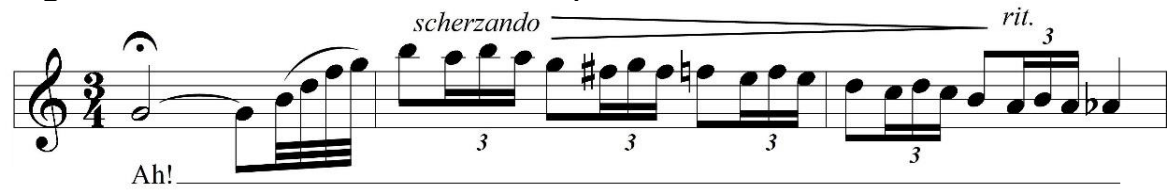

No entanto, ele muda progressivamente essa vocalidade colorida, ágil e fluida para uma linha mais escura, dramática e pesada à medida que o drama avança para a tragédia em direção ao quarto e último ato. Os pontos focais dramáticos e progressivos desta modificação do humor e vocalitá, do texto e da música, da melopoética, são a tentativa de estupro de Gonzales (segundo ato), a prisão dos Aymores (terceiro ato) e, finalmente, a perda de seu pai (quarto ato). É notável como Gomes, antes do ataque de Gonzales, apresenta a famosa "Ballata", na qual a música é muito mais próxima do bel canto que na introdução do 
primeiro ato. O uso intensivo de trilhos, roulades e cadenzas na aria parece confirmar a idealização de uma casta e pura donzela, antes de enfrentar a crua realidade da vida e transformar-se em uma mulher em condição de sofrimento. Parece claro que Gomes adota esta vocalitá belcantística não como uma opção sem sentido, mas intencionalmente para enfatizar na música a diferença dramática entre o fim da jovem sonhadora para a mulher madura que enfrentará vivos conflitos emocionais e o perigo físico real até o final da ópera. A Figura 5 mostra a extensa curva melódica da frase musical que abrange uma oitava inteira, terminando em um Sí grave. Em uma abordagem melopoética, esta solução resulta em uma súplica melódica impressionante que também será usada por Ponchielli em La Gioconda em 1894.

Figura 5 - A. C. Gomes. // Guarany. $2^{\circ}$ ato. Scena e duetto.

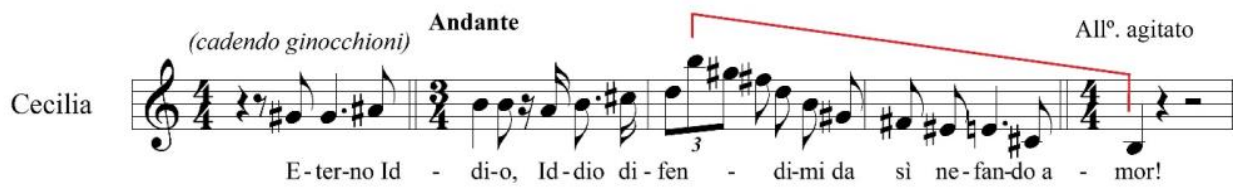

Uma abordagem semelhante é usada no $3^{\circ}$ ato quando Cecilia enfrenta um perigo extremo nas mãos dos Aymores, mas de repente o chefe está impressionado com a beleza da jovem e a preserva de ser agradida pelos guerreiros indianos. Mais uma vez, a vocalitá que Gomes usa para expressar esse repentino alívio de tensão em um comentário íntimo de Cecilia de que a modificação do comportamento do selvagem se deveu a uma virtual interferência das orações de seu pai, Don Antonio, é o registro baixo e a marcada abordagem silábica do texto (Figura 6).

Figura 6 - A. C. Gomes. // Guarany. $3^{\circ}$ ato. Scena e duettino.

Cecilia

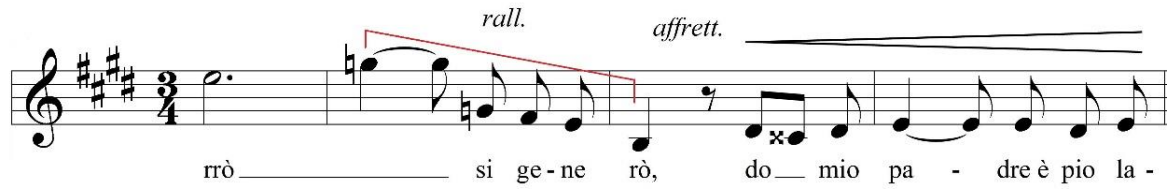


No $4^{\circ}$ ato, Cecilia tem pouca intervenção. De qualquer forma, a vocalitá prescrito por Gomes é próximo daquela do $3^{\circ}$ ato e com o mesmo pathos de tristeza e sofrimento para o futuro que ela prevê para seu amado pai. A curva, como mostrado anteriormente, pode ir para o registro agudo e, em seguida, descer para a parte mais grave da tessitura denotando a situação sombria que a jovem enfrenta (Figura 7).

Figura 7 - A. C. Gomes. // Guarany. $4^{\circ}$ ato. Grand scena e terzetto finale ultimo.

Cecilia

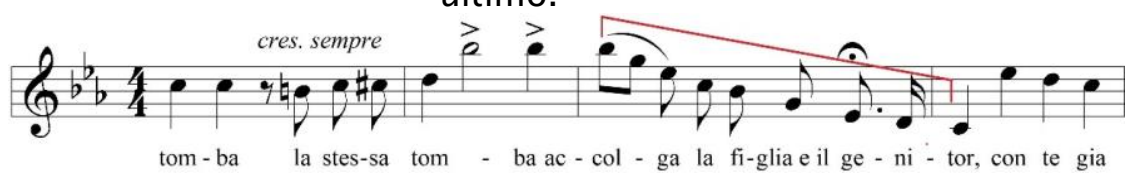

La Gioconda de Amilcare Ponchielli exige do papel principal um soprano dramático de qualidade, uma verdadeira atriz cantante (attrice cantante) de acordo com a definição no período. Na cena final, Barnaba chega à casa de Gioconda para reivindicar seu crédito sexual. Esta já havia decidido se suicidar em vez de entregar seu corpo. Embora criticado por alguns autores, esta cena final, com texto de Arrigo Boito, é uma das tramas mais bem elaboradas da história da ópera italiana e tratada com excelente domínio musical por Ponchielli. É surpreendente como Ponchielli lida com o vocalitá do solista de acordo com a condição emocional da personagem. Do mesmo modo que Gomes, ele muda o vocalitá da soprano para um tom mais leve e alegre, não só para reforçar o contraste do momento dramático como para estabelecer um ambiente de graça e sensualidade exigido por Gioconda para enganar com segurança Barnaba enquanto ela se prepara para esfaquear-se, pondo fim a seus tormentos. Depois de uma vocalitá sombria usada até agora ao longo do ato, nesta seção, Ponchielli faz uso de roulades e apogiaturas para denotar uma música leve e vívida, que contrasta ironicamente com o humor sombrio da personagem (Figura 8). 
Figura 8 - A. Ponchielli. La Gioconda. $4^{\circ}$ ato. scena e duetto finale.

Gioconda

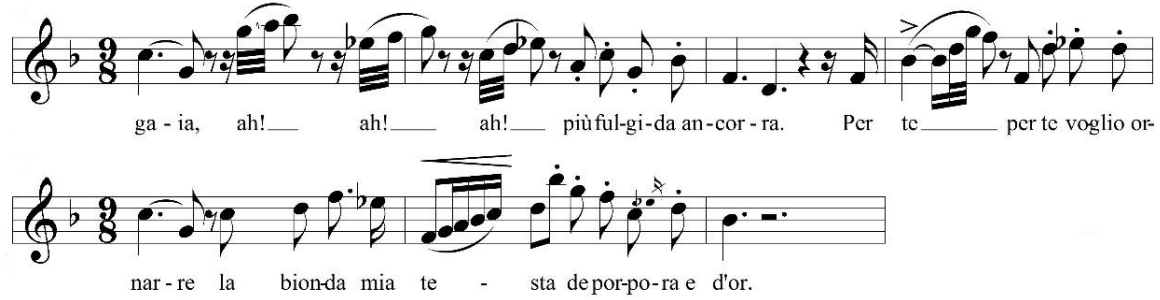

Outra característica da vocalitá de Gomes e Ponchielli no período de transição é o uso de amplos intervalos com significado dramático. Mais uma vez, Fosca (1873) é um dos primeiros exemplos de óperas em que este expediente dramático é usado efetivamente, o que pode ser visto na frase de Fosca (Figura 9), na qual encontramos, em sequência, dois amplos intervalos ascendentes de sétimo menor.

Figura 9 - A. C. Gomes. Fosca. $1^{\circ}$ ato. Preghiera.

Fosca

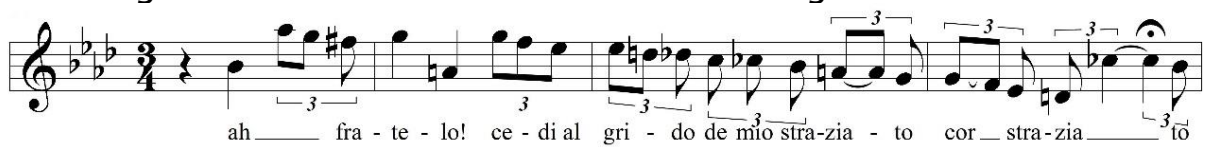

É importante notar aqui o uso dramático desse arranjo de intervalos. A instabilidade emocional dos eventos está sempre presente, subjacente ao fato recitado. Fosca, no exemplo da Figura 9, pede a oportunidade de ficar com o homem que ela ama. A frase, fragmentada pela angulação dos amplos intervalos, comenta esta situação de instabilidade psicológica, ao ponto em que a Fosca pretende esfaquear seu rival. Em La Gioconda, a mesma instabilidade está presente em um enredo mais amplo: temos cinco personagens com relações conflitantes (Laura com Alvise e Enzo; Enzo com Alvise, Barnaba e Gioconda; Gioconda com Enzo e Barbaba e Barnaba com Gioconda). No entanto, Ponchielli usa o mesmo procedimento técnico para descrever essa instabilidade em seus momentos cruciais. No primeiro ato, quando Barnava acusa sua mãe de feitiçaria, a intervenção de Gioconda para protegê-la é por meio de um amplo salto descendente (Figura 10), 
observando que a forte sílaba da palavra "menti" está na nota mais alta do intervalo.

Figura 10 - A. Ponchielli. La Gioconda. $1^{\circ}$ ato. Somossa.

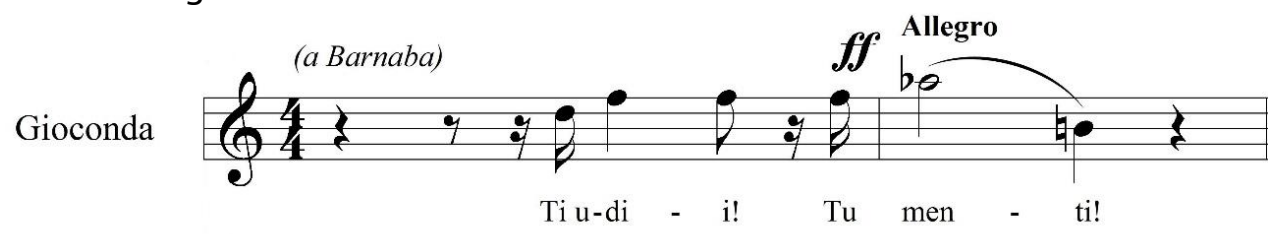

Da mesma forma, na introdução do dueto do segundo ato, Laura e Giocona expressam o clímax de sua angústia em frases muito curtas com amplos intervalos descendentes. Gioconda, na discussão ríspida com a rival, termina sua peroração exortando-a a escapar. O clímax desta peroração é, corretamente, um amplo salto descendente e a palavra "fuggi!" Está no registro muito baixo depois de um Lá agudo (Figura 11).

Figura 11 - A. Ponchielli. La Gioconda. $2^{\circ}$ ato. Duetto.

Gioconda

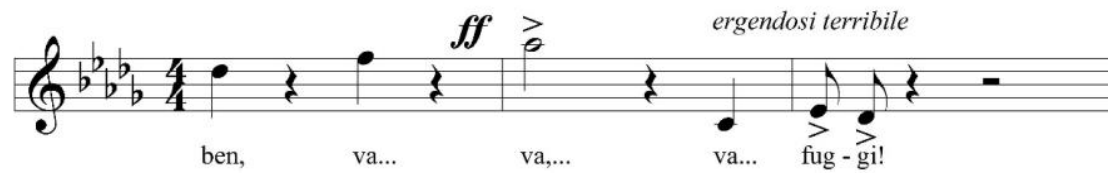

Para Laura, Ponchielli usa o mesmo procedimento ao momento que a rival afirma que seu amor por Enzo é real e intenso. Para começar sua famosa frase (L'amo comme il fulgor del creato!), Laura contesta Gioconda com repetidos "Menti!" E, novamente, Ponchielli destaca o clímax da angústia de Laura com uma sequência de amplos intervalos descendentes que ele diminui progressivamente para permitir uma sensação de autocontrole antes de expressar apaixonadamente a pureza de seu amor por Enzo. (Figura 12). 
Figura 12 - A. Ponchielli. La Gioconda. $2^{\circ}$ ato. Duetto.

Laura

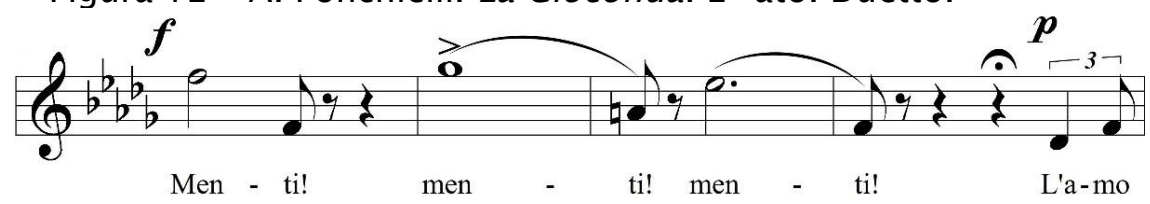

Ainda em Gomes, podemos ver outro exemplo em Maria Tudor, em que há dois saltos, um descendente de mais de uma oitava e outra uma oitava ascendente, separados por um só compasso (Figura 13).

Figura 13 - A. C. Gomes. Maria Tudor. $4^{\circ}$ ato. Monologo e aria.

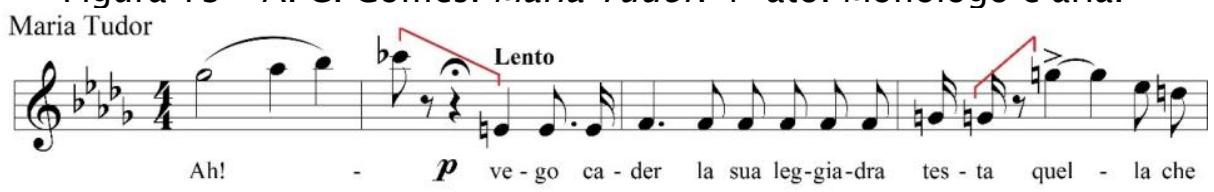

Da mesma forma, em Maria Tudor, o protagonista está sob forte sofrimento emocional ao cantar a frase do exemplo citado, uma vez que ela mesma enviou seu amado à forca e a incerteza de sua vontade a deixa em profunda instabilidade emocional. Assim, Gomes usa esses saltos para ilustrar adequadamente essa instabilidade.

Deve-se notar que o uso de amplos intervalos, certamente, não foi criado por Gomes ou nenhum de seus contemporâneos. A diferença está na inserção desses intervalos dentro do conjunto idealizado da frase vocal e, portanto, na vocalitá, e sua associação direta com o texto e a situação psicológica da cena em que são usados. $\mathrm{Na}$ verdade, encontraremos exemplos do uso de intervalos amplos sem essas características e, portanto, sem esse resultado, em compositores atuando muito antes desse período. Este é o caso de Rossini em Le Siège de Corinthe, uma revisão do Maometto II, estreada em 1826 em Paris (Figura 14). Aqui, os amplos intervalos têm o principal objetivo de demonstrar a capacidade vocal, uma característica do bel canto que estava sendo desconstruída, curiosamente, pelo mesmo Rossini. 
Figura 14 - G. Rossini. Le Siège de Corinthe. $1^{\circ}$ ato. Scena e tercetto.

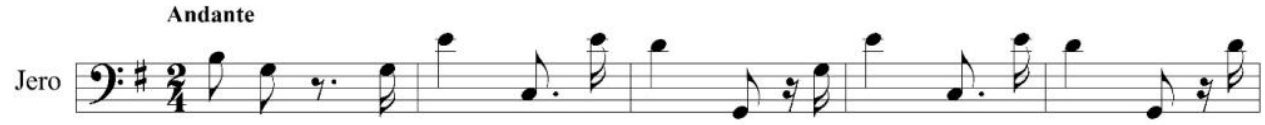
for - tc;

Um caso mais curioso é o de La Juïve de F. Halèvy, de 1835. Embora muito mais cedo do que as obras dos compositores do período de transição, encontramos um exemplo premonitório do uso de amplos intervalos com forte conteúdo dramático. Este é o caso na cena final do terceiro ato, quando Rachel denuncia Leopold publicamente de ser mante de uma judia. A cena ocorre nada mais nada menos que na frente da população de Constanza e da noiva de Leopoldo, a princesa Eudoxia! O exemplo musical da Figura 15 descreve o intenso conteúdo emocional desta cena e a objetividade e a crueza do texto que leva, além disso, a uma situação de imprevisto e revelação, ou seja, um claro exemplo de coup de theatre. O ponto climático é a revelação e é onde ocorre o salto do intervalo, mas não como efeito do virtuosismo vocal como no exemplo de Rossini. O salto está dentro do tom lógico da frase, precedendo e formando parte da cadência I 6/4 - V - Im, onde a tensão insuportável da cena é descarregada nas pessoas, que reagem fortemente à revelação do fato sem precedentes - o marido da princesa católica tem um caso com uma jovem judaica.

Aparentemente, este expediente meticulosamente elaborado não era comum na época, e sua clara relação com a prática dos compositores da transição pode ser explicada pela forte influência da grand-opéra, que, como já foi mencionado, foi um dos elementos de releitura por este grupo. O que se pretende perguntar é se esses compositores da Transição haviam detectado e analisado a presença desse tipo de tratamento, por exemplo, em Halèvy, pois deve ser lembrado que esta ópera estreou em Alla Scala apenas em 1865. Essa data é interessante porque significa trinta anos após a estreia em Paris, mas é o ano em que Gomes já está em Milão estudando no Conservatório. 
Figura 15 - F. Halévy. La Juive. $3^{\circ}$ ato. Cena final.

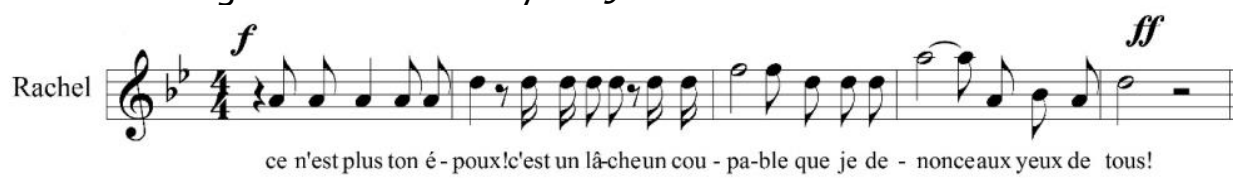

Fosca, novamente, é um ponto de partida interessante para uma discussão de um último exemplo das modificações do tratamento de linha vocal pelos compositores do período de transição. A relação entre discurso dramático e musical se intensifica e se aproxima. A declamação dramática, muitas vezes de caráter enérgico, assume preponderância. Esta opção de tratamento da frase vocal está de acordo com a busca da continuidade do discurso musical, que Verdi estava procurando (e alcançou) em Rigoletto de 1851. Por outro lado, as cenas de conexão entre as seções já não possuem o caráter contemplativo ou puramente narrativa de fatos ocorridos. Agora, os fatos acontecem em tempo real, e texto e música descrevem reações psicológicas consistentes com seu conteúdo dramático. Há uma necessidade de expressar algo real, traduzir uma sequência de sentimentos suscitados ou resultantes de um fato concreto. Conforme discutido em outro lugar (Powers, 1897; Beguelli, 2004), esta é uma das características da decomposição da Solita forma de Rossini, um dos marcos do período de transição, à qual Gomes deu uma contribuição ímpar. A Fosca introduziu muitas novidades no melodrama desse período e, por esse motivo, pode ser usado novamente para exemplificar o que foi dito sobre a mudança na vocalitá.

$\mathrm{Na}$ cena final do segundo ato, Gajolo, para salvar Fosca da fúria da população, explica que ela está louca. Sua reação é muito convincente e o tratamento musical dado por Gomes, a declamação musical que ele usa para este segmento é muito eficaz e característico desta nova modalidade de vocalitá. Fosca sente-se indignada com o artifício usado por seu irmão na mesma medida em que ela também reconhece sua loucura por buscar um amor impossível. A série de intervenções vocais curtas, usando uma tópica paradigmática de Gomes, sublinhado pelo mesmo tema rítmico na orquestra, a frase ascendente para Sol \# e o 
salto repentino para um Ré e Dó \# graves sublinham claramente todos os diferentes estados de espírito que afetam a mente de Fosca em um curto período de tempo (Figura 16). Do ponto de vista dramático, a solução alcançada por Gomes é muito adequada para dizer o mínimo.

Figura 16 - A. C. Gomes. Fosca. $2^{\circ}$ ato.

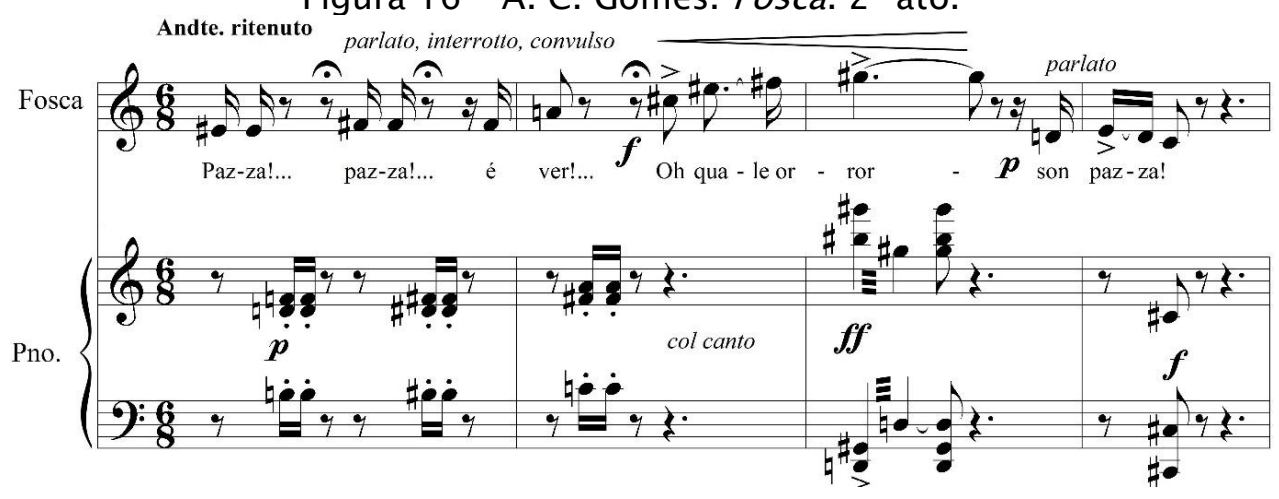

\section{Considerações finais}

O período de transição é estudado em profundidade por Nicolaisen (1980) e descrito claramente por Cesari (2002). Julian Budden (2002, p. 263) discute o período de transição sob o título de "A Problem of Identity (Italian Opera 1870, p. 90). Considerando o renovado interesse acadêmico sobre a ópera italiana no final do século 20 , é difícil negar que esse período tenha existido, assim como sobre sua relevância na evolução do melodrama italiano da segunda metade do século XIX. Não há dúvidas de que foi um período curto e que a produção operística de seus representantes não se constituiu em notáveis obras-primas. No entanto, a relevância deste período está bem documentada por Giger (2007), afirmando que nesse período a ópera italiana mudou, uma mudança gradual e até certo ponto sem consequências imediatas. Este é um período de descontrução de cânones e convenções. Na verdade, essa parece ser a principal característica do período de transição, o abandono progressivo das convenções por compositores que não eram necessariamente revolucionários, como Gomes e Ponchielli e com uma 
contribuição mais tardia de Catalani, provavelmente o mais capaz entre eles, mas cujos trabalhos de maior maturidade não se disponibilizaram devido à sua curta vida. A contribuição mais relevante do período de transição e seus compositores foi pavimentar o caminho para o Verismo do Giovane Scuola de 1890 através de uma ruptura contínua com as convenções. Atualmente, as óperas de Gomes e Ponchielli estão recebendo um merecido revival. I Lituani, I/ Figliuol Prodigo, Fosca, II Guarany e Salvator Rosa foram realizados nos Estados Unidos da América, no Brasil e na Europa nos últimos anos do século XX e novas produções ainda estão sendo realizadas no novo século. É uma recuperação tardia, mas melhor tarde do que nunca. Outro ponto relevante é que Verdi, em sua reclusão, nunca esteve ausente do que estava acontecendo no mundo musical e certamente estava ciente do que Gomes e Ponchielli estavam fazendo, além de notar o desmantelamento progressivo da velha tradição, a qual ele próprio começou com seu Rigolleto. Ademais, Aida e o revisado Don Carlos são sinais claros de que o velho mestre estava recluso, mas não adormecido.

\section{REFERENCIAS}

BEGUELLI, Marco. Morfologia dell'opera italiana da Rossini a Puccini, in Enciclopedia della musica, diretta da Jean-Jacques Nattiez, vol. IV (Storia della musica europea), Torino, Einaudi, 2004, pp. 895-921

BUDDEN, Julian. The Operas of Verdi, 3rd volume. From Don Calros to Falstaff. Revised edition. Oxford: Claredon Paperbacks, 2002.

CESARI, F. La «TRANSIZIONE». Disponível em: <http://www.univirtual.it/corsi/2002_l/\%20cesari/lezione08/download/I ezione08.rtf> Acesso em: 12 jan. 2006. 
CELLETTI, Rodolfo. Caratteri della vocalità di Verdi. In: Atti del $3^{\circ}$ Congresso Internazionale di Studi Verdiani. Parma: Instituto di Studi Verdiani, 1974. p. 81-88.

CLEMENT, Félix; LAROUSSE, Pierre. Dictionnaire des opéras (Dictionnaire lyrique) : contenant l'analyse et la nomenclature de tous les opéras, opéras-comiques, opérettes et drames lyriques représentés en France et à l'étranger depuis l'origine de ces genres d'ouvrages jusqu'à nos jours. Ed. Arthur Pougin. Paris: Laroussse, 1905, 1326p.

GIGER, Andreas. "Verismo": Origin, Corruption and Redemption of an Operatic Term. Journal of the American Musicological Society, n. 60, p. 271-315, 2007.

GOSSET, Phillip. Diva and Scholars: performing Italian opera. Chicago: University of Chicago Press, 2006. p. 704

MILLER, Richard Securing Baritone, Bass-Baritone, and Bass Voices. New York: Oxford University Press, 2008, p. 9.

NICOLAISEN, Jay. Italian opera in transition, 1871-1893. Michigan: Ann Arbor, 1980.

NOGUEIRA, Lenita Waldige Mendes Nogueira. Joana de Flandres de Carlos Gomes: obra de transição. In: Maria Alice Volpe (Org.) Atualidade da Ópera. Rio de Janeiro: Universidade Federal do Rio de Janeiro, 2012. p. 269-283.

POWERS, Harold.S. "La solita forma" and "The use of Conventions". Acta Musicologica, v. 59, Fasc.1, 1987. p. 65-90.

RUTHERFORD, Susan. The Prima donna and opera, 1815-1930, Cambridge University Press, 2006.

SENICI, Emanuelle. Words and musics. In: The Cambridge Companion to Verdi. Scott L. Balthazer, ed. Cambridge; Cambridge University Press, 2004.

VIRMOND, Marcos da Cunha Lopes. Carlos Gomes no contexto da transição da ópera italiana. In: Maria Alice Volpe (Org.) Atualidade da Ópera. Rio de Janeiro: Universidade Federal do Rio de Janeiro, 2012. p. 195-221. 